\title{
CONSUMPTION TOWARDS ENVIRONMENTALLY FRIENDLY CONSUMER BEHAVIOUR: THE CASE OF PLASTIC BAGS
}

\author{
Elena Horská', Alim Pulatov² , Ashirali Abdirashidov ${ }^{* 3}$ \\ 'Slovak University of Agriculture in Nitra, Slovakia \\ ${ }^{2}$ EcoGIS Center, Tashkent Institute of Irrigation and Melioration, Tashkent, Uzbekistan \\ ${ }^{3}$ International Economic Relation, Tashkent Islamic University, Tashkent, Uzbekistan
}

\begin{abstract}
This article analyses past and current state of plastic bags usage and reviews the major challenges in addressing the issue of its reduction with emphasis on failure and success of the chosen policy. Given the heterogeneous impacts of government policies, it is important to understand the consumer behaviour and motivation for purchasing plastic bags. This can help to make a fundamental shift in reduction of plastic bags usage by the demand side, which supplement government's efforts to address the issue from the supply side.
\end{abstract}

Keywords: consumption, consumer behaviour, plastic bags, eco-friendly bags

\section{Introduction}

Negative externalities of production processes are widely acknowledged and examined phenomena. Reduction of $\mathrm{CO}_{2}$ as well as physical materials causes immense difficulties in solving the question of waste-free production process and favourable environment. In this aspect, the issue of plastic bags takes special role.

Convenience in use, functionality as well as low cost of plastic bags contributed to their popularity both among retailers and consumers (UNEP, 2004). Currently, majority if not all of small consumer goods, in particular, food products are transported in plastic bags as it is noted by Rayne (2008).

Thanks to the invention of plastic by Alexander Parkes in 1862, currently there are

Table 1 Plastic Bags Statistics

\begin{tabular}{|l|c|}
\hline Statistic & Number \\
\hline Total number of plastic bags used worldwide annually & 1 trillion \\
\hline Total number of plastic bags China consumes every day & 3 billion \\
\hline Total number of plastic bags used every minute & 1 million \\
\hline Total number of years it takes for a plastic bag to degrade & 1,000 years \\
\hline Total amount of plastic bags that were discarded in 2008 & 3.5 million tons \\
\hline Total amount of plastic floating in every square mile of ocean & 46,000 pieces \\
\hline Average amount of plastic bags consumed per family in 4 trips to a grocery store & 60 \\
\hline Per cent of plastic made every year that will end up in an ocean & $10 \%$ \\
\hline Total amount of plastic bags used by U.S. citizens every year & 100 billion \\
\hline Average amount of plastic bottles a U.S. household will use each year & 500 plastic bottles \\
\hline Percent of household waste that is plastic & $11 \%$ \\
\hline
\end{tabular}

Source: Smart Green Tips, Earth 911 billions of plastic bags in the world, which firmly joined to a set of consumption habits due to their convenience in usage. At the same time, plastic bags do not disintegrate and while burned, they emit $\mathrm{CO}_{2}$. It is noticeable that even in the USA which have rather well-developed infrastructure of recycling, only around $5 \%$ of used plastic bags comes to the recycling stage, $45 \%$ is buried in waste storages or left without final attention. Scientists present empirical evidence that plastic bags constitute $7-9 \%$ of produced waste.

The technological advances that led to lighter plastic did not necessarily lighten the problems created by plastic bags but magnified it: lighter bags are not suitable to be re-used and heavy items need to be double bagged.

\section{Data and methods}

The aim of the present paper is to analyse past and current state of plastic bags usage and to bring a brief review of the major challenges addressing the issue of its reduction with emphasis on failure and success of the chosen policy.

Numerous reports and analytical findings came to the conclusion that plastic bags result in significant ecological problems and useless waste of energy resources. For example, after introduction of restrictions on production and usage of plastic bags in China, around 1.6 million tons of oil has been saved.

For example, the pie chart shows the statistics for the Hambantota region of Sri Lanka, which was examined as a case study by JICA in 2014. The results show that $29 \%$ of total solid waste produced by business entities is represented by plastic bags. Indeed, it is only second to paper and carton waste (39\%) and followed by food waste (20\%) in the list of the items examined.

The same category of numbers for households, given in following chart demonstrates a similar pattern. Plastic bags take $16 \%$ of shares in total solid waste produced by households, being third after food waste and tree leaves.

\section{Results and discussion}

In an attempt to reduce the side effects caused by packaging, governments give their full attention to plastic bags, which as it was mentioned earlier, became fundamental concern due to their wide-spread usage by consumers (Ritch et al. 2009). In particular, Ritch et al. (2009) target 


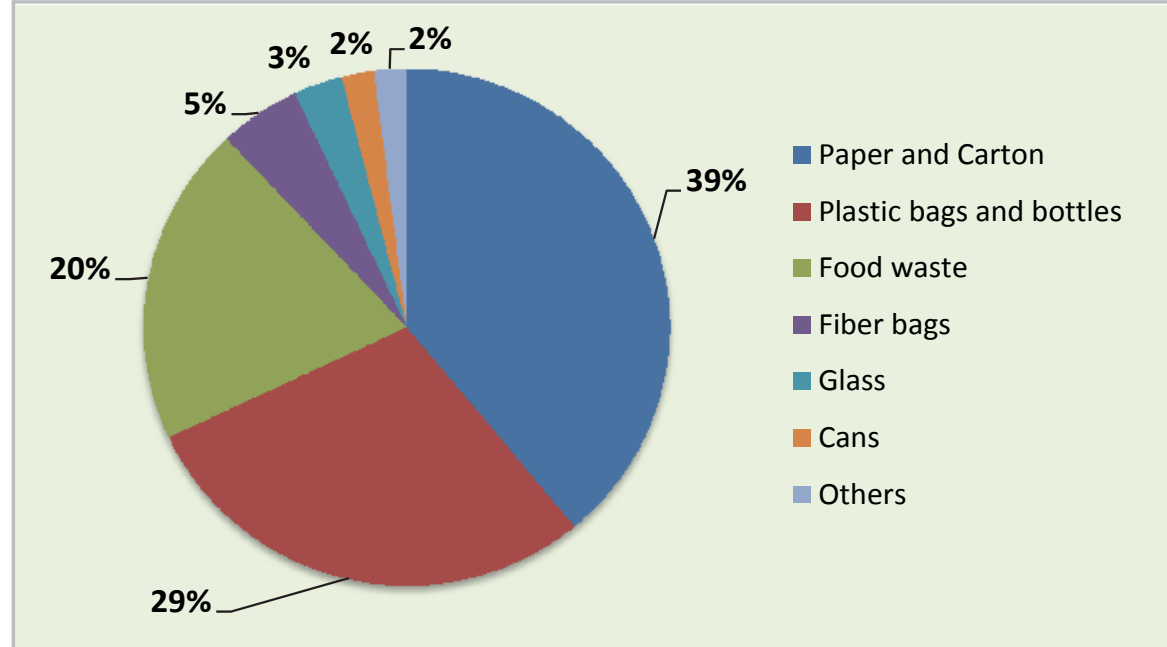

Figure 1 Solid Waste of Business entities by Types

Source: SATREPS. 2014. Waste amount and composition survey in Hambantota MC. JCA

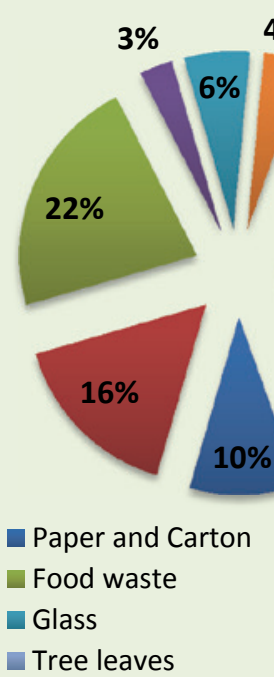

$4 \%$

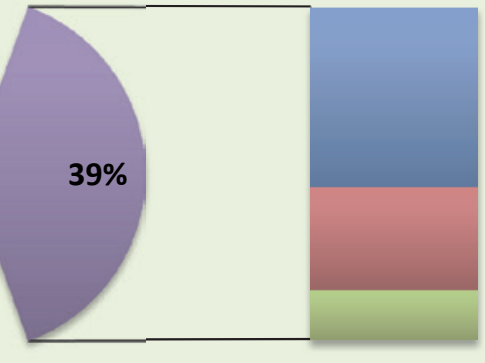

$21 \%$

$6 \%$

- Plastic bags and bottles

- Fiber bags

cans

Coconut Shells

Figure 2 Solid Waste of Households by Types

Source: SATREPS. 2014. Waste amount and composition survey in Hambantota MC. JICA

the solution of the minimum usage of plastic bags by affecting the consumer behaviour. In a cross country approach, Albuquerque (2009) provides the possible correlation of elevated rate of consumption of plastic bags by consumers and natural catastrophes. Fabro et al. (2007) describe the transformation channel as a collectively unconscious one, where consumers attaining the habit of plastic bags usage implicitly contribute to degradation of environment and eco-system.

To solve the problems created as consequences of plastic bags, one might outline two approaches. One is the top-down approach where governments initiate state policies on plastic bags and pursue relative or total abandoning of plastic bags production process by various fiscal instruments. The bottom-up approach might be described as a process initiated by consumers and directed towards the usage of ecologically sound production of process of bags. Of course, the best approach means the mixed solution where governments' initiatives might be fully supported by consumers and induce changes in behaviour patterns.

\section{Experiments of plastic bags reduction}

In the cross-country example, one might bring the case of Italy where starting from January 1 , 2011, usage of plastic bags made of oil products. This process started in 2006, went through discussions and an approval process in legislative chambers. Similar case has been observed in the UK. In June of 2008, Chinese government prohibited production, sale and usage of ultrathin plastic bags. As a structural component of this act, it was prohibited to freely distribute plastic

Table 2 Reduction instruments

\begin{tabular}{|c|c|c|c|c|c|c|c|c|c|c|c|c|c|c|}
\hline Instruments & $\check{3}$ & 跑 & 호 & $\begin{array}{l}\stackrel{8}{*} \\
\frac{0}{2}\end{array}$ & 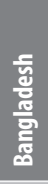 & 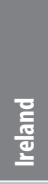 & 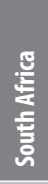 & 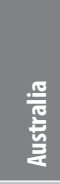 & 올 & 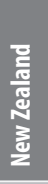 & 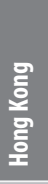 & 胥 & 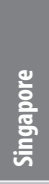 & $\begin{array}{l}\text { 욯 } \\
\text { 동 }\end{array}$ \\
\hline Ban & & & & & $*$ & & & & * & & & * & & \\
\hline Earmarked Charges & & & & & & * & & & & & & & & \\
\hline Charge system & & * & & & & & & & & & & & & \\
\hline Charges & & & & & & & * & & & & & & & \\
\hline Introduction of cleaner alternatives & & & & & & & & & & * & & & & \\
\hline Penalty fee & & & & * & & & & & & & & & & \\
\hline Pollution taxes & & & * & & & & & & & & & & & \\
\hline Public information campaigns & & & & & & & & & * & * & * & & * & \\
\hline Product/Technology/ Performance/Standards & * & & & & & & & & & & & & & \\
\hline Recycling & & & & & & & & & & * & & & & * \\
\hline Voluntary agreements & & & & & & & & * & & & & & & \\
\hline
\end{tabular}




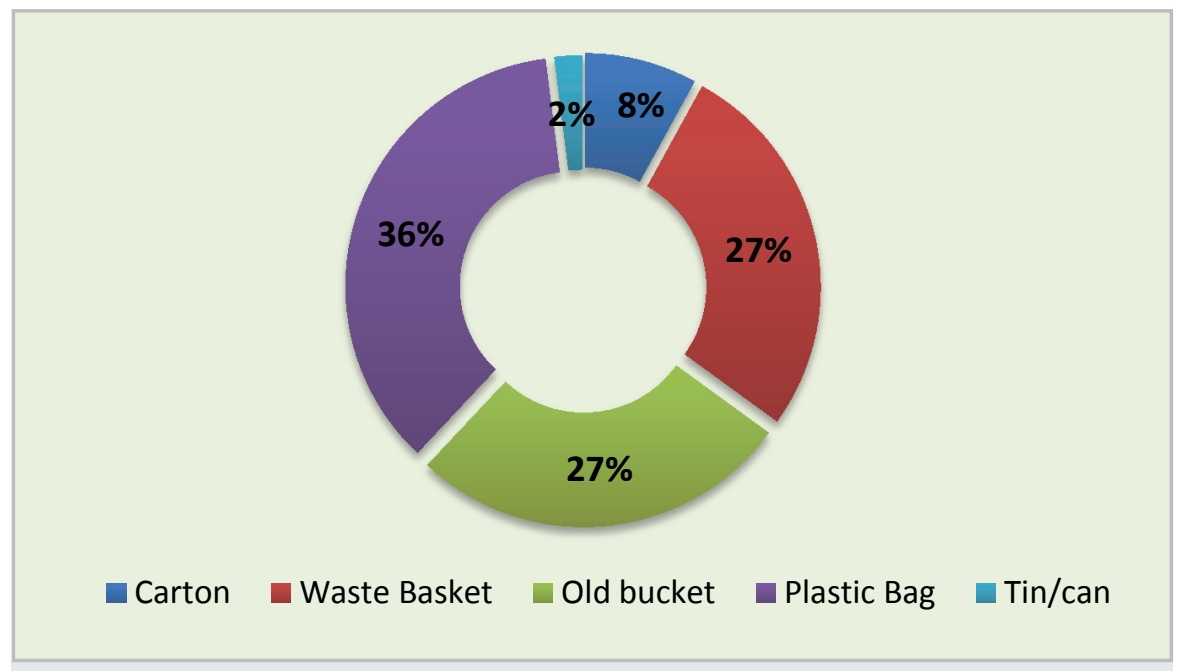

Figure 3 Consumer products used as Containers by business entities Source: SATREPS. 2014. Waste amount and composition survey in Hambantota MC. JICA

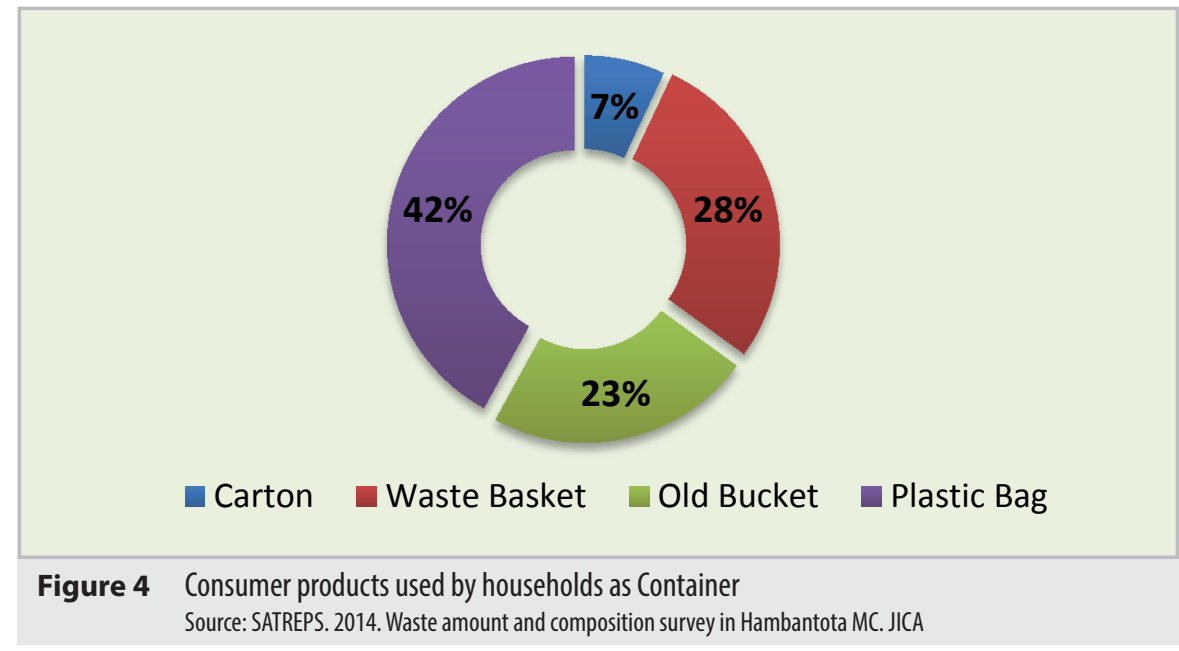

bags by supermarkets and stores to consumers. Measures mirroring those of Chinese are also introduced in Mexico, starting from 2011, where violation of the regulations results in penalty fees.

Among the instruments reducing the usage of plastic bags one can mention special charges or levies, penalty fees, pollution taxes, public information campaigns and other measures depicted in Table 2.

Turning to practices of the abovementioned measures in the cross-country example, we can look at Ireland which in an effort to affect the behaviour of consumers adopted a levy on different types of plastic bags. Originally, Ireland started to see the chance of the plastic bag levy in 1994, but the proposal of such a levy was prepared only in 2000 . The desired system of collecting and using the revenue was supposed to balance with consumers' understanding: the revenue was used solely on environmental purposes and levy itself was directed towards changing the perception and habit of using plastic bags. Obtaining of positive results depended on collaboration and understanding of different actors across industries, sectors and regions, central and local government bodies, revenue collectors, and consumers.

In this aspect one should emphasize the notion of anticipation. In the empirical literature, it can be clearly seen that anticipation of change in legislation itself might cause the desired change and adjustment which is expected by implementing the legal act. Similarly, in the case of Ireland, retailer companies themselves reported that in anticipation of the new levy, consumers already started to adjust their behaviour which has translated into the increased usage of reusable bags. As a result, it is documented that taken measures constituted significant impact on consumer behaviour: per capita usage of plastics bags dropped 16 times, from 328 to 21 bags. The levy allowed collecting around 3.5 million euro which has been spent to tackle environmental issues. As the time has passed, there has been a slight increase in per capita usage of plastic bags coming to 2006, where per capita usage constituted 31 bags. To cope with the problem, authorities decided further increase of levy which caused drop in usage both in 2007 and 2008.

As a precautionary measure one needs to emphasize the nuances such measures might cause: reverse effect or insignificance of the measures if implemented in inappropriate ways. Inspired by the achievement of Ireland, other countries have used its scheme to implement similar measures in the own respective countries. Similarly, South African government introduced levy for plastic bags thicker than the determined number of microns. However, such necessity or obligation for levy charging was not distributed in unitary manner, but only included relatively large retail stores. As a result, they found themselves in disadvantaged position with respect to other retailers, which caused the break of fulfilment of agreed levy charge.

To avoid such negative impacts of financial burdens directly imposed through prices and affecting the competitiveness of business, it is noticeable to mention the case of the USA, in particular San Francisco. In 2006, the Governor Arnold Schwarzenegger approved the Plastic Bag and Litter Reduction Act. Interesting characteristic of the Act was that though it was encouraging the educational aspects and promoting recycling, it clearly outlined the case that local agencies cannot be able to impose levies or fees as well as additional recycling requirements on retailers.

Similarly, one of the largest retail stores in Uzbekistan, Korzinka.uz, launched a campaign of introducing eco-friendly bags. Recent statistics provided by the UN News and the Mass Media Department show that annually, 60,000 consumers are served in Korzinka, where they bring to their homes 2 or 3 plastic bags on average. Cumulatively this might result in significant shift of environmental balance.

To estimate the impact of the abovementioned policy programmes or changes in consumption patterns, governments might conduct short-term, mid-term and long-term policies. Depending on relative success or failure of the measures, needed amendments and modifications might be applied, contributing to better overall results.

In doing so, we need to understand the relative usage or intended functionality of plastic bags by consumers. The same research statistics carried out by JICA in 2014 for the Hambantota region in Sri- Lanka found out that business entities use plastic bags also as waste containers, and it takes the largest share (36\%) in the total number of types of examined containers. 
The same applies for households. The total of $42 \%$ of households uses plastics bags as containers as opposed to waste baskets or old buckets. This is a developed habit due to the convenience of plastics bags which might be difficult to change in short way.

In terms of methodology, one might go for the option of randomized control trials which is characterized as a quasi-experimental approach. In this case, government agencies might need to collect the data before and after the legislation act directed towards the changes in consumer behaviour. In doing so, this might allow comparing two different regions out of which one was exposed to a change in legislation and one was not. Randomized control trial or treatment effects method might require matching of specific characteristics before and after assigning the treatment, i.e. introduction of a legal act.

of course, the convenience which such plastic bags brought out will be difficult to restrain from. However, collective action might be necessary to overcome the greater cost which unthinking and floppy actions by consumers might bring out. This might be especially true in the context of developing countries where improper balance of sustainability and growth can be observed.

In practical aspects, changes in behavioural patterns of consumers might be brought by education programs, broader explanation of unintended consequences of such usage of plastic bags and developing of specific culture of general consumption of eco-friendly products.

The above-mentioned method of randomized control trial is widely used to assess the programme effect, especially in the development and economic growth context. However, due to being an instrument, it can be successfully employed to carry out impact assessment of new legislation on chosen variables of outcome, in particular, consumption of plastic bags. The principal component analysis or the factor analysis methods allowing reducing the dimensionality might also help to understand the main underlying variables causing the biggest variation in correlation with number of plastic bags.

\section{Conclusion}

To sum up, with increased levels of consumption, the increase in usage of plastic bags might cause unbalanced state of ecology and economy. To avoid this trap and achieve steady state economic growth with sustainable environment, government policies might be directed towards the reduction of plastic bags usage. Depending on given socio-economic circumstances, countries choose instrument affecting consumers' behaviour indirectly and reducing the number of plastic bags used. Even though some instruments such as fixed fees on usage of plastic bags might be successful in one country, the same application of measures in different context might not bring the desired result due to idiosyncratic region-specific characteristics. Once the policy instrument is chosen, government might conduct assessment of the policy measures, where methods like randomized control trial or principal component analysis might be of great use.

\section{References:}

AVALLONE, I. - GIRALDI, J. - OLIVEIRA, S. 2012. Conscious Consumption: A Study on Plastic Bags' Consumers in Brazil. In International Journal of Psychological Studies, vol. 4, 2012, no. 1, pp. 122-134.

CONVERY, C. - MCDONNELL, S. - FERREIRA, S. 2007. The most popular tax in Europe? Lessons from the Irish plastic bags levy. In Environ Resource Econ, 2007, no. 38, pp. $1-11$.

ENDS Europe. 2013. England to introduce plastic bag charge from 2015. 16 September 2013.

INFORMATIONAL ECO-NETWORK. 2015. Billions of plastic bags. Article. Web [http://sreda. uz/index.php?newsid=508]. Accessed 2.06.2015.

RITCH, E. - BRENNAN, C. - \& MacLEOD, C. 2009. Plastic bag politics: Modifying consumer behaviour for sustainable development. In International Journal of Consumer Studies, 2009, no. 33, pp. 168-174. Retrieved September 14, 2010, from Business Source Premier database. D0I 10.1111/j.1470-6431.2009.00749.x

SCOTLAND'S PLASTIC BAG USAGE down $80 \%$ since $5 p$ charge introduced. Web [http:// www.theguardian.com/environment/2015/apr/17/scotland-plastic-bag-usagefalls-after-5p-charge-introduced]. Friday 17 April 201512.57 BST. Accessed online: July 10, 2015.

STATISTICS BRAIN RESEARCH INSTITUTE. Plastic Bag Statistics Web [http://www. statisticbrain.com/plastic-bag-statistics/]. Accessed online 2.06.2015.

SWAIT, J. - ADAMOWICZ, W. 2001. Choice environment, market complexity, and consumer behavior: a theoretical and empirical approach for incorporating decision complexity into models of consumer choice. Organizational Behavior and Human Decision Processes, vol. 86, 2001, no. 2, pp. 141-167. http://dx.doi.org/10.1006/ obhd.2000.2941.

UNITED NATIONS. 2015. News and Mass media Department. Uzbekistan launches ecobags. Web [http://www.unmultimedia.org/radio/russian/archives/167632/\#. VW2tns_tmko]. Accessed online 2.6.2015.

UNITED NATIONS ENVIRONMENT PROGRAMME (UNEP). 2015. website:UNEP-GEF projects on implementation of national biosafety frameworks. Web [http://www.unep.ch/ biosafety/impbackground.htm]. Accessed online 2. 6. 2015.

\section{Contact addresses}

Ashirali Abdirashidov, International Economic Relation, Tashkent Islamic University, A.Kadiriy 11, Tashkent 100011, Uzbekistan 